\title{
Evolution and Medicine: An Inquiry-Based High School Curriculum Supplement
}

\author{
Paul M. Beardsley • Molly A. M. Stuhlsatz • \\ Rebecca A. Kruse • Irene A. Eckstrand • \\ Shefa D. Gordon • Ward F. Odenwald
}

Published online: 8 October 2011

(C) Springer Science+Business Media, LLC 2011

\begin{abstract}
Evolution and Medicine is a curriculum supplement designed by the National Institutes of Health (NIH) and the Biological Sciences Curriculum Study (BSCS) for high school students. The supplement is freely available from NIH's Office of Science Education (OSE) as a part of the NIH curriculum supplement series. Development of the supplement was a collaborative effort that included input from a panel of experts in medicine, evolution, education, and educational technology. In total, the curriculum supplement includes five inquiry-based lessons that are integrated into the BSCS 5E instructional model (based on constructivist
\end{abstract}

P. M. Beardsley $(\bowtie) \cdot$ M. A. M. Stuhlsatz $\cdot$ R. A. Kruse

BSCS (Biological Sciences Curriculum Study),

5415 Mark Dabling Blvd,

Colorado Springs, CO 80918, USA

e-mail: pmbeardsley@csupomona.edu

\section{A. Eckstrand}

National Institute of General Medical Sciences, Division of Genetics and Developmental Biology,

Center for Bioinformatics and Computational Biology,

45 Center Drive, Room 2AS.25K, MSC 6200,

Bethesda, MD 20892-6200, USA

\section{S. D. Gordon}

National Eye Institute, Office of Program Planning and Analysis, Building 31, Room 6A23 MSC-2510, 9000 Rockville Pike,

Bethesda, MD 20892-6200, USA

\section{W. F. Odenwald}

National Institute of Neurological Disorders and Stroke,

Neural Cell-Fate Determinants Section,

Bethesda, MD 20892-6200, USA

\section{Present Address:}

P. M. Beardsley

Center for Excellence in Mathematics and Science Teaching and Department of Biological Sciences, CEMaST 4-2-515 California

State Polytechnic University,

3801 W. Temple Ave.,

Pomona, CA 91768, USA learning theory). The goal was to develop a 2-week curriculum to help students understand major concepts of evolution using the dynamic, modern, and relevant context of medicine. A diverse group of students and teachers across the US participated in a formative evaluation of a field test version of the curriculum. High school students made significant learning gains from pretest to posttest, with a relatively large effect size for student understanding of common ancestry and a relatively small effect size for student understanding of natural selection. There was no statistically significant difference in achievement gains between white students and all other racial/ethnic categories. Overall, the evaluation suggests that a curriculum that emphasizes the role of evolution in medicine, uses a constructivist instructional model, and is grounded in inquiry is relatively well-received by teachers and students and shows promise for increasing student learning in evolution.

Keywords Evolution · Natural selection · Common ancestry · Instructional model · Inquiry · High school . Evolution and medicine

Understanding evolution is critical for true biological literacy (Dobzhansky 1973). However, evolution education research highlights the many difficulties in teaching and learning about evolution. One major barrier is the numerous misconceptions that students and the general public have about evolution, including both natural selection (Bishop and Anderson 1990) and interpreting evolutionary trees and common ancestry (Naegle 2009; Perry et al. 2008). Misconceptions about the nature of science also contribute to difficulties in understanding evolution (Sandoval and Reiser 2004). Many scientists and educators recognize that most curriculum materials for teaching about evolution do not help students address their prior conceptions. Moreover, few curricula portray evolution as a current and dynamic science, nor do they show why understanding evolution is relevant (Hillis 2007). 
To help address this issue, the National Institutes of Health (NIH) and the Biological Sciences Curriculum Study (BSCS) partnered to develop a curriculum supplement that is freely available to high school teachers and their students. As part of its mission to discover and expand knowledge in biomedical sciences to enhance the Nation's health and to motivate and train the next generation of scientists, NIH has developed 19 educational supplements to primary and secondary science curricula on topics ranging from infectious disease, sleep, hearing, drug addiction, and DNA. The concepts from each supplement align with relevant concepts in the National Science Education Standards (National Research Council 1996). The curriculum supplements are available through NIH's Office of Science Education website (http://science.education.nih.gov). Lessons within the supplements reinforce the concept of "science" as a verb, the active process of investigating and understanding the natural world rather than a noun, a static body of knowledge to be memorized. Evolution is also an active process that underlies the extraordinary diversity and complexity of all living things, and it touches on every aspect of modern medical science. Evolution is fundamental to understanding how our genomes are organized, why new infectious diseases are continuously arising and how disease-causing organisms become resistant to drugs, and why certain disorders are common in some populations and not in others. Evolutionary thinking aids scientists in developing animal models of disease that enable drug testing and discovery. Evolutionary comparisons based on genetic data have become a powerful tool that scientists and physicians are now using to identify and understand genetic disorders and to identify genes that, because of their importance to life processes, have persisted for millions of years.

The major goal of the project was to develop a relatively short curriculum supplement that leveraged evidence-based approaches to teaching about evolution, using evolution in medicine as a context. Medicine is a useful vehicle to demonstrate the relevance of evolution because evolution profoundly impacts problems faced by doctors and healthrelated events in the news. This supplement illustrates that understanding evolutionary processes is fundamental to understanding and promoting human health and to developing better medical interventions. The supplement provides teachers with access to new resources to support the biology curriculum and provides students with opportunities to participate in inquiry-based learning and investigate evolution in action using real examples relevant to their lives.

A review of the evolution education literature (Beardsley et al. 2011) helped the design team identify specific pedagogical approaches that had some evidence for effectiveness when used to help students learn about evolution. Two main features highlighted in the supplement are described below.
(1) Teaching science as inquiry with a strong emphasis on developing explanations and arguments based on evidence (Sandoval and Reiser 2004; Passmore and Stewart 2002; Asterhan and Schwarz 2007). Throughout the supplement, students are asked to develop explanations and evaluate alternate explanations in light of evidence they have gathered.

(2) Promoting conceptual change by first asking students to record their initial ideas about major concepts, then providing students with experiences and investigations to help them recognize and confront any misconceptions. Throughout their experiences, students should frequently reflect on how their thinking has changed (Bransford et al. 2000; Vosniadou 2008) To help implement a constructivist approach, we used a rigorously tested instructional model (the BSCS 5E instructional model) that helps students understand content and use higherlevel reasoning (Wilson et al. 2010).

Table 1 Student learning outcomes for the Evolution and Medicine supplement as determined by the advisory board

1. Students will understand the importance of evolutionary comparisons for studying biomedical problems.

- Students will understand the importance of biologists studying genomes of a large number of other organisms and other humans.

- Students will appreciate the value of using other organisms as model systems for studying health-related issues in humans.

- Students will recognize that the rates of evolutionary change in genetic sequences give clues about the role of purifying and diversifying selection on that region.

- Students will be able to describe how rates of evolution relate to medical applications (for example, how the mechanisms of evolution affect the development and use of vaccines).

2. Students will understand the role of evolution in diseases.

- Students will understand that evolution explains many aspects of why humans (as a species) are the way they are.

- Students will understand that health and disease are related to our evolutionary history.

- Students will understand that selection is acting at the level of the phenotype, and phenotype is a product of genes, environment, and their interactions.

- Students will understand that natural selection influences health only to the extent that it influences reproductive success.

- Students will understand that evolution often involves tradeoffs which can influence health.

3. Students will understand the role of evolution in infectious diseases, including evolution of antibiotic and antiviral resistance.

- Students will be able to describe how evolutionary processes can affect antibiotic/antiviral resistance.

- Students will understand the role of evolutionary theory in the development and use of vaccines and other treatments.

- Students will understand the role of evolutionary theory in identifying and understanding the origin and trajectory of pathogens. 
In remaining sections, we describe the curriculum development process used by NIH and BSCS, briefly describe the five lessons that make up the curriculum supplement, and provide data from the formative evaluation of a field-test version of the supplement.

\section{Curriculum Development Process}

The development process for Evolution and Medicine was guided by principles from Understanding by Design (Wiggins and Tighe 2005) and used procedures that have been in place at BSCS since the organization's founding in 1958. Experts in evolution, education, biomedical research, medicine, and educational technology collaboratively participated at multiple points in the project, and master teachers were involved throughout. The first step in the process involved convening an advisory board meeting to identify the key student learning outcomes for the curriculum. Three key outcomes (each with further associated outcomes) were identified (see Table 1).

To help students meet the learning goals for the curriculum, an external design team of high school teachers, subject matter experts, and representatives from NIH and BSCS met for several days of lesson development and writing. This team, with the input of the advisory board, provided initial designs for the activities, including identifying relevant data sets, studies, and approaches used in evolution and medicine. Additionally, the team developed exemplary ideas for using web-based educational technology. Using input from the advisory board and external design team, curriculum developers at BSCS, in partnership with multimedia experts and representatives from $\mathrm{NIH}$, put structure and form to the activities and materials, culminating in a close-to-complete version that was field-tested with high school students across the country. The results of the field test are further described in the section entitled Formative Evaluation of Evolution and Medicine.

Results from the field test were analyzed to give the advisory board, curriculum developers, and multimedia experts evidence on which to base their decisions for modifying and improving the curriculum. After implementing suggested changes to the curriculum, the revised materials were sent to ten external scientific reviewers, as well as multiple reviewers within NIH. Suggestions from the reviewers were implemented into a final version of the curriculum. In total, the development and revision process lasted over two years.

\section{Brief Description of the Lessons}

Five lessons were developed to meet the student learning goals of the supplement. In total, the lessons require an average of 12 50-minute periods. The curriculum was designed to function as a coherent unit of instruction, and the lessons were carefully sequenced within the BSCS 5E Instructional model (Bybee et al. 2006). Individual lessons are not intended to stand alone. Three of the lessons have an associated web-based interactive component. The preferred mode of teaching is to use the webbased interactives, however, alternatives are provided that only use print-based materials for classrooms without access to the internet. The web-based interactives also have alternative interactives to provide accessibility to people with disabilities. A brief description of the lessons follows. We only describe the web-based option for lessons that have both a web-based and print-based option.

Lesson 1, Engage-Ideas about the Role of Evolution in Medicine The goal of "Engage" activities is to involve students in interesting scenarios to pique their interest and allow them to share their current understanding (prior knowledge) of a concept or idea. Lesson 1 consists of two separate activities. In the first activity, "Outbreak!", students learn about a fictional outbreak of methicillin-resistant Staphylococcus aureus (MERSA) based on similar outbreaks in actual U.S. high schools. Designed to be brief, the goal of the activity is to make students' thinking about genetic variation and natural selection evident to the students themselves and to the teacher using a scenario that may have touched students' lives. Many introductory biology textbooks for high school contain a description of the evolution of antibiotic resistance. Thus, this activity was chosen to help students feel comfortable as they start the supplement and to help teachers gauge what the students understand from their previous experiences. Similar to an approach for undergraduate students described by Bray Speth et al. (2009), students focus on and practice using five principles related to natural selection throughout the supplement (Table 2).

The second activity of Lesson 1, Models and Medicine, is designed to reveal students' prior understanding of

Table 2 The five major principles of natural selection that are emphasized in the supplement, based on work by Bray Speth et al. (2009)

Major principles of natural selection

Variation: Individuals within a population vary in many traits, including physical and biochemical ones.

Inheritance: Some of the differences in traits among individuals can be passed from parents to offspring.

Origin of variation: Some of the variation in traits among individuals has a genetic basis. This variation originated, often many generations ago, as mutations - changes in the genetic information that are random with respect to the needs of the organism.

Fitness: Both the environment and the traits individuals possess affect survival and reproduction. Individuals with heritable traits that enable them to better survive and reproduce in a particular environment will leave more offspring.

Evolutionary change in populations: The frequency of traits and the alleles that affect those traits change in a population over time. 
common ancestry and their ability to interpret evolutionary trees, or phylogenies. The activity centers on students investigating and interpreting data for the Pax6 gene and its resulting protein, which is involved in eye development during embryogenesis. Students examine amino acid sequences for the Pax6 protein from humans and three species that are model organisms in medical studies: mice, zebrafish, and fruit flies. Students also interpret the results of genetics experiments involving all four species and consider their interpretations in light of a phylogeny of the four species. After making an initial attempt, students are given a brief orientation in interpreting phylogenies; then they revise their original answers. At the conclusion of the activity, students document their initial ideas about the following question, "How does shared ancestry explain why scientists can use model organisms to learn about human health?" Students return to their answers to this critical question later in the supplement.

Lesson 2, Explore-Investigating Lactose Intolerance and Evolution The goal of "Explore" activities is to provide an experience for all students to generate and analyze data so they can begin to develop an explanation of the major concepts of how natural selection affects human health and why understanding common ancestry is important for medicine. These shared experiences are meant to give all students a meaningful basis upon which to reflect, regardless of their prior experiences. In this activity, students begin by conducting a laboratory investigation in which they test simulated patient samples for lactase activity. Next, students explore a web-based, interactive map of Africa, Asia, Europe, and the Middle East that shows the percentage of people in different regions that are lactase persistent or lactase nonpersistent, based on reports from the scientific literature (Enattah et al. 2007; 2008; Gerbault et al. 2009; Tishkoff et al. 2007; Fig. 1). Students explore the data by geographic region, by gender, or by age (infants versus adults) and develop initial explanations for the patterns they observe. As the lesson proceeds, students learn, through guided inquiry, about the genetic basis for lactase persistence and the different mutations that cause lactase persistence in different parts of the world. The lesson concludes with students considering two alternative hypotheses for the evolution of lactase persistence: the culture-historical hypothesis and the calcium absorption hypothesis. Students are divided into two groups and each analyzes data that generally supports one or the other hypothesis. Students then engage in a brief debate that focuses strongly on the use of evidence.

\section{Lesson 3, Explain-Evolutionary Processes and Patterns Inform Medicine "Explain" activities give the learners relevant experiences through which they can fully construct an explanation of a major concept and guide them to compare their explanation to explanations accepted by science. Given that the curriculum supplement provides students with opportunities to learn about two major concepts,}

Investigating Lactose Intolerance and Evolution

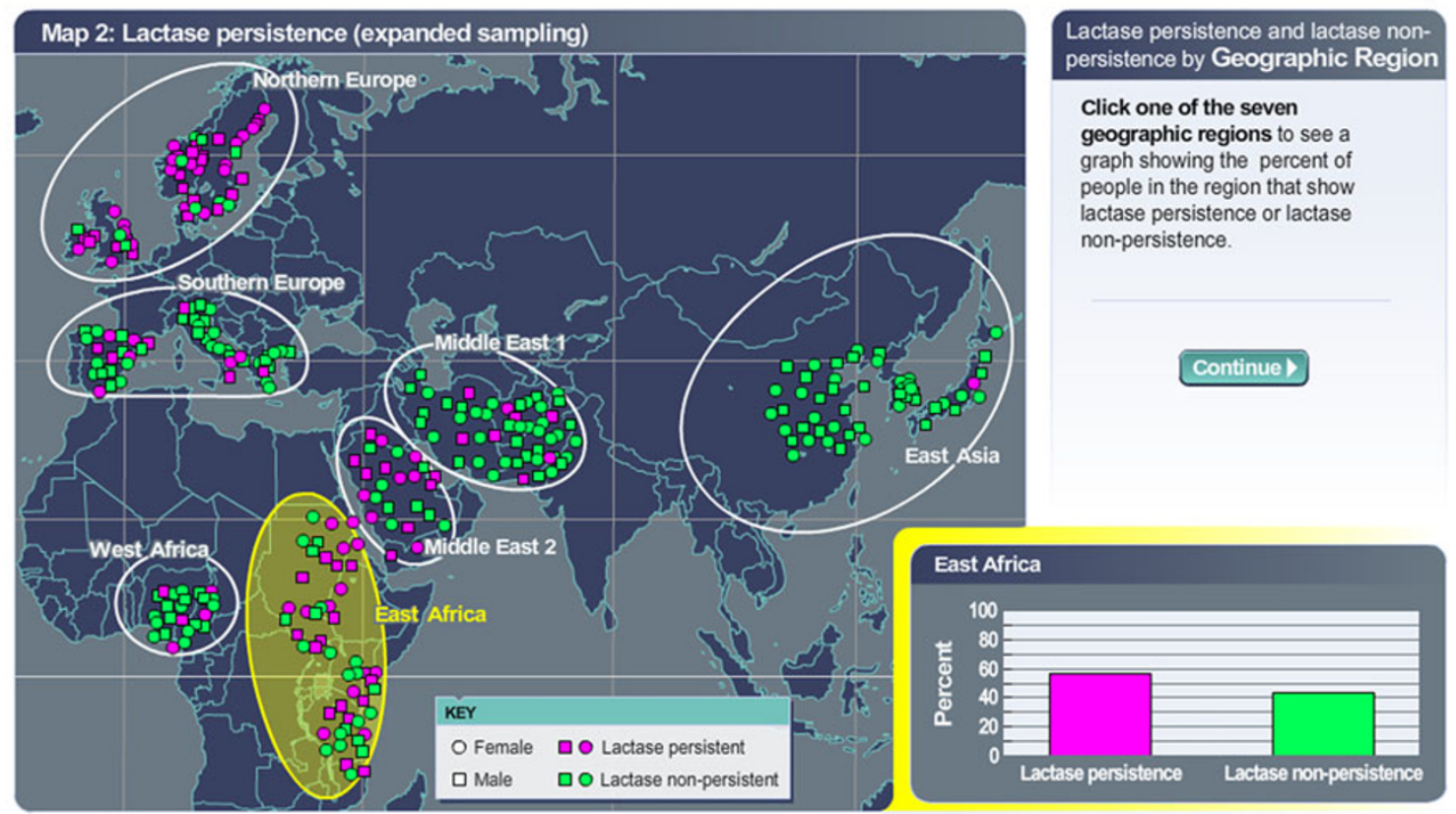

Fig. 1 Screenshot of a map showing the percentage of people in different parts of the world that are lactase persistent or lactase nonpersistent, based on reports from the literature 
natural selection and common ancestry, there are two activities that make up the "Explain" lesson. In the first activity, "Investigating a Mystery Disease," students use information from medical tests and a virtual microscope to diagnose the cause of anemia in patients from Papua New Guinea. Through this analysis, students recognize that many of the patients suffer from alpha-thalassemia. Again, through guided inquiry, students recognize that the geographic distribution of alphathalassemia overlaps with areas in which malaria is a serious health issue. Students then use data from published studies (Williams et al. 2005; Fowkes et al. 2008) and the principles of natural selection to explain the relatively high frequency of the disease in certain populations. Students are formally introduced to the five features of natural selection for the first time in this lesson, and they are given the opportunity to revise their explanations based on natural selection from the "Engage" and "Explore" lessons.

Alpha-thalassemia was chosen as an example to build on the fact that many students learn about sickle cell anemia and malaria in typical introductory high school biology courses. The advisory and design teams felt that learning of a second disease that follows a pattern similar to sickle cell anemia's could help students apply their understanding of the concepts of natural selection to a broader range of problems.

The goal of the second activity, "Using Evolution to Guide Research," is to help students more fully explain why understanding common ancestry is important for medical research. Students learn to use a tool called an EvoPrinter, developed by researchers at NIH (Yavatkar et al. 2008), for comparing and visualizing differences in genetic sequences across multiple species (see Fig. 2). To develop an EvoPrint, researchers define the sequence from one species as a reference sequence. In the EvoPrint in Fig. 2, a portion of the human sequence for the IRF6 gene was chosen as a reference. Researcher can then add homologous sequences for the IRF6 gene from multiple species. Nucleotides that remain the same in all the sequences are represented with a capital letter in a high contrast color. Nucleotides that differ in any of the sequences are represented with a lowercase letter and a color that blends into the background color. In this manner, conserved sequences stand out. Specific mutations in IRF6 cause Van der Woude syndrome, which causes a specific form of cleft lip and palate (Kondo et al. 2002). Students use the EvoPrint to identify regions of the IRF6 gene that have not changed over vast amounts of evolutionary time. After identifying specific regions, students calculate the amount of time that is represented in an EvoPrint by analyzing the relationships among all the species in the comparison using a phylogenetic tree in which the branch lengths are proportional to time (chronogram). Students then reflect on how common ancestry explains why a similar gene is found in such a broad array of species and why understanding the function of genes in other organisms contributes to our understanding of how the gene may function in humans. Finally, students are given the opportunity to revise the answers they gave about model organisms and common ancestry in Lesson 1.

Lesson 4, Elaborate-Using Evolution to Understand Influenza "Elaborate" activities ask students to apply their

\section{Evoprint Comparison}

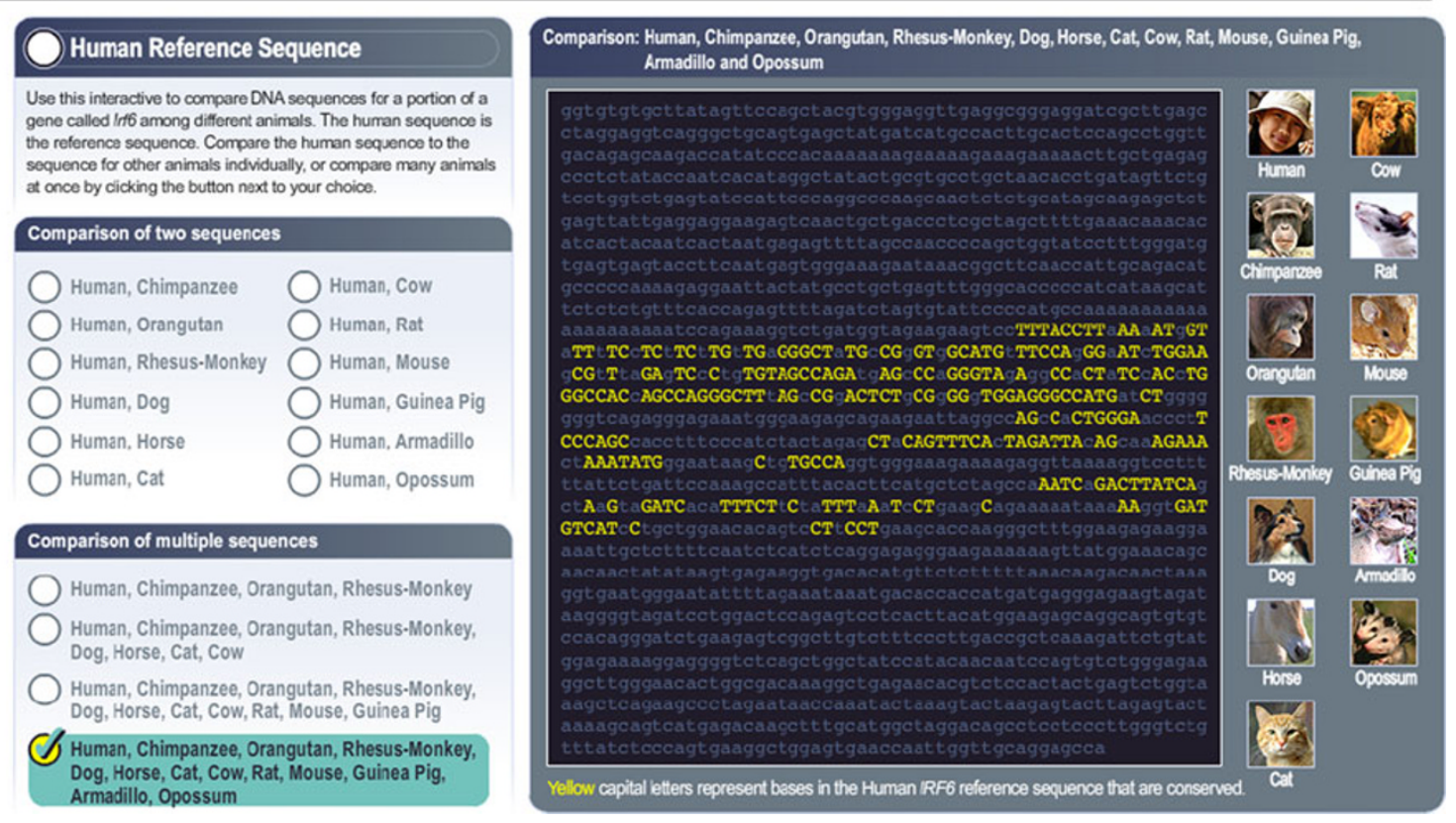

Fig. 2 A multi-species EvoPrint for a portion of the IRF6 gene, using the human sequence as a reference 


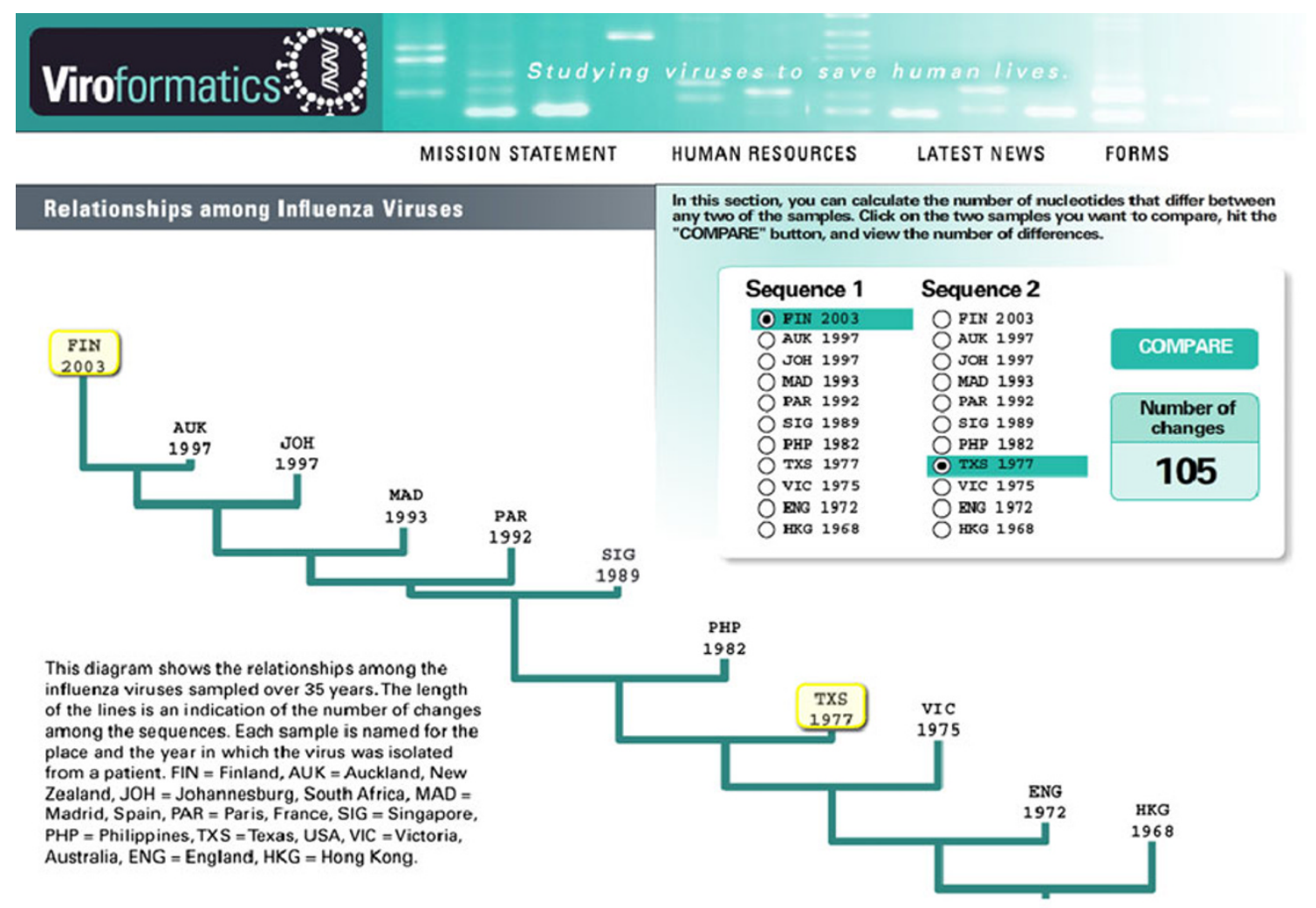

1 BACK 1 VRAL GENOME DATABASE

Fig. 3 A phylogenetic tree for 11 influenza viruses isolated over 35 years, based on hemagglutinin sequences

current understanding of a concept to a new situation or to delve more deeply into the concept. In Lesson 4, students explore the evolution of influenza viruses over time, using genomic resources and bioinformatic tools to help answer the question "Why is a new flu vaccine needed every few years?" Throughout the lesson, students have to integrate their understanding of both natural selection and common ancestry. After gaining some background knowledge about influenza and influenza viruses, students align portions of the sequence from the hemagglutinin gene from three influenza viruses. Students then learn about genomic resources, see an alignment and an evolutionary tree for 11 influenza viruses for a larger portion of the hemagglutinin gene, and compute the number of changes that have accumulated in 35 years (Fig. 3). The sequences students analyze are a subset of those analyzed by Smith et al. (2004) in their study of the relationship between genetic evolution and antigenic distance in influenza viruses. To accomplish their task, students are given access to a fictional genome database which was designed to be a simplified version of the publicly available one housed by the National Center for Biotechnology Information. Students then describe how natural selection influences the evolution of influenza as they learn more about how the influenza virus interacts with the immune system. The rapid rate of evolution in influenza is part of the explanation for why a new flu vaccine is needed every few years.

Lesson 5, Evaluate-Evaluating Evolutionary Explanations "Evaluating" activities give students the opportunity to demonstrate to themselves and to their teacher what they have learned over the course of the curriculum supplement. In this lesson, students use what they learned about evolution and medicine to review an article that focuses on vitamin $\mathrm{C}$ and evolution, written for a school publication. The article, written by a fictional fellow student, contains statements based on common misconceptions for students' understanding of natural selection and common ancestry. The students' task is to try to find specific errors, explain the incorrect statements, and correct the information. In the final portion of the activity, students reflect on the multiple examples of natural selection they explored throughout the supplement. Students are asked to choose one of the examples and create a labeled illustration demonstrating the process of natural selection. In a class discussion, students are asked to draw connections among all the different examples of natural selection they explored in the supplement. This step is included to help students recognize that they explored general principles that apply to all examples of natural selection. 


\section{Formative Evaluation of Evolution and Medicine}

The curriculum developed by NIH and BSCS was field-tested in classrooms across the country in the winter and spring of 2010. This formative evaluation of the curriculum was designed to gather data on the feasibility and usability of the materials from both teachers and students. We also sought to begin to explore data on the effectiveness of the lessons to help students achieve the specific learning outcomes outlined by the advisory board. The advisory board, NIH, and curriculum developers at BSCS used the findings to revise and improve the final version of the curriculum supplement.

\section{Methods}

BSCS attempted to include a diverse group of teachers, schools, and students in the field test. In making our selections, we sought a balance in geographic location, schools from urban, suburban, and rural areas, students representing a variety of ethnic, economic, and cultural backgrounds; a range of teacher backgrounds, from relatively new teachers to more experienced teachers; and a balance of genders among teachers. BSCS selected 12 primary field-test teachers who attended a two-day field-test orientation at BSCS headquarters. Fifteen additional teachers were invited to participate in the secondary field test. Secondary field-test teachers did not attend the fieldtest orientation. Instead, materials were sent directly to them, and they were asked to use them according to the guidelines in the "Teacher Background Materials" without any additional professional development.

Feasibility and usability were measured with evaluation of materials surveys that were administered online to teachers, with a paper and pencil version for students. For each of the five activities, teachers answered 11 to 13 Likert-style and open-ended items. Teachers also answered five overall questions about the supplement. Teachers were queried for their opinions about the impact of the lessons on student interest, effectiveness in meeting learning outcomes, conceptual and practical difficulties with the lessons, value of the graphics and web components, and changes they recommended. We also gathered feedback from students who participated in the field test. Students responded to 23 Likert-style questions about their interest in the supplement, how they thought the lessons affected their level of understanding, the usefulness of the graphics and web-based materials, and other general questions about the quality and effectiveness of the supplement. Students also provided open-ended items concerning changes they would like to see in the supplement.

Student knowledge tests were administered before and after students participated in the field test to enable us to gain preliminary insights into the effectiveness of the lessons in helping students achieve the specific learning outcomes. Pre/posttests consisted of ten multiple choice items, each followed with a confidence rating. Six multiple choice questions were derived from published instruments to meet the assessment needs of the high school student population. The use of similar questions facilitated comparisons of our results and those from other evolution education researchers working with undergraduate students (Bray Speth et al. 2009). Three items were adapted from the Conceptual Inventory of Natural Selection (CINS; Anderson et al. 2002), two from a "tree-thinking" concept inventory (Naegle 2009), and one from a study of middle school student learning in evolution (Beardsley 2004, based on items in Bishop and Anderson 1990). Four new questions were developed that measured students' understanding of concepts specifically aligned with the role of evolution in medicine.

The lessons were field-tested with a diverse population of students $(n=976)$ and teachers across the country. Complete evaluation materials were received from 11 primary field-test teachers and three secondary field-test teachers, representing 43 different classes. The large majority of students $(74 \%)$ were in regular introductory biology courses. Complete pre/posttests were received from a total of 792 students. The student population for the study was diverse (Table 3), with over $50 \%$ of students in one of the non-white categories. Nearly $50 \%$ of the students reported receiving either free or reduced-price lunch. More females participated in the field test than males $(57 \%$ were female) because one of the field-test teachers taught in an all-girls school. Most of the students were in the grades targeted for the module: grades 9 and 10 (Grade 9, 31\%; Grade 10, 41\%; Grade 11, 14\%, Grade 12, 6\%). English was not the primary language at home for $20 \%$ of students.

\section{Results from the Field Test}

Overall, teachers had a favorable opinion of the curriculum supplement. Mean teacher ratings of effectiveness on general questions about the lessons, graphics, and websites were in the

Table 3 Summary of race/ethnicities for students completing the pretest and posttest $(n=792)$. Students were instructed to select all race/ethnicity categories that apply to them, explaining why the sum is greater than $100 \%$

\begin{tabular}{lr}
\hline Race/ethnicity & Percent \\
\hline African American & 28.5 \\
American Indian or Alaska Native & 7.2 \\
Asian & 19.0 \\
Hispanic or Latino/a & 18.3 \\
Native Hawaiian or other Pacific Islander & 12.6 \\
White & 47.3 \\
Other race/ethnicity & 16.4 \\
\hline
\end{tabular}


Table 4 Teacher evaluation of the materials

\begin{tabular}{lllll}
\hline Lesson & $\begin{array}{l}\text { Difficulty } \\
\text { for students }\end{array}$ & $\begin{array}{l}\text { Implementation } \\
\text { difficulty for } \\
\text { teachers }\end{array}$ & $\begin{array}{l}\text { The lesson } \\
\text { was engaging } \\
\text { for students }\end{array}$ & $\begin{array}{l}\text { Overall } \\
\text { effectiveness }\end{array}$ \\
\hline 1 & $3.2(0.7)$ & $2.7(1.0)$ & $4.7(1.1)$ & $5.1(1.2)$ \\
2 & $3.4(0.5)$ & $3.2(0.8)$ & $5.2(0.7)$ & $5.4(0.8)$ \\
3 & $3.9(0.4)$ & $3.1(0.5)$ & $5.3(0.7)$ & $5.3(0.9)$ \\
4 & $3.4(0.6)$ & $2.9(0.8)$ & $5.0(0.8)$ & $4.7(1.0)$ \\
5 & $3.3(0.5)$ & $2.6(1.1)$ & $\mathrm{n} / \mathrm{a}$ & $4.7(1.4)$ \\
\hline
\end{tabular}

For questions that asked about difficulty of the materials for students and teachers, the following scale was used: 1 = "Extremely Easy," 2 = "Somewhat Easy," 3 = "Just Right," 4 = "Somewhat Difficult," 5 = "Extremely Difficult." The question about engagement was scored on a scale from 1 to 6 with $1=$ "Strongly Disagree" to $6=$ "Strongly Agree." Overall effectiveness used a scale from 1 to 6 with $1=$ "Very Ineffective" to $6=$ "Very Effective." Numbers in parentheses are standard deviations. Lesson 5 was an evaluate activity, so teachers did not comment on whether or not the lesson engaged their students

range of "Agree a Little" to "Strongly Agree" (or in the range of "Moderately Effective" to "Very Effective"). Table 4 shows that teachers perceived the difficulty of the lessons for their students to be in the "Just Right" to "Somewhat Difficult" range. Implementing the materials was ranked between "Somewhat Easy" to "Just Right."

Comments from teachers revealed that field-test students were engaged in learning about evolution in medicine and that students responded well to the inquiry-based approach. Teachers felt that the materials were relevant and interesting to students and that relevance worked to help students build a strong understanding of the content. The following quotes from field-test teachers illustrate these points.

The interactive materials were invaluable because they enabled the students to look for patterns in the data more effectively and because they enabled the students to do the kind of data analysis (e.g. the blood testing) which they otherwise would not normally be able to do.

I think the selection of diseases that were used in relating and understanding evolution and medicine are very relevant and appropriate. The selection is very critical to the integration of evolutionary thinking in medicine so students can deeply understand the
Table 5 Student evaluation of how the curriculum influenced their understanding

\begin{tabular}{lcc}
\hline Statement & Mean & $\begin{array}{c}\text { Standard } \\
\text { deviation }\end{array}$ \\
\hline $\begin{array}{l}\text { 1. My understanding of the role of evolution } \\
\text { in medicine increased. }\end{array}$ & 4.54 & 1.15 \\
$\begin{array}{l}\text { 2. My understanding of why humans are } \\
\text { susceptible to disease increased. }\end{array}$ & 4.58 & 1.10 \\
$\begin{array}{l}\text { 3. My understanding of how natural selection } \\
\text { informs medicine increased }\end{array}$ & 4.47 & 1.12 \\
$\begin{array}{l}\text { 4. My understanding of how analyses of genetic } \\
\text { sequences inform medicine increased. }\end{array}$ & 4.31 & 1.17 \\
\hline
\end{tabular}

Students were asked to rate their agreement with the following statements on a 6-point scale. $1=$ "Strongly Disagree," $2=$ "Disagree," 3 = "Disagree a Little," 4 = "Agree a Little," $5=$ "Agree," 6 = "Strongly Agree"

concepts of evolution and allow them to get involved in analyzing theories and ideas of evolution.

Using different experimental results to really see how scientists compile and use data (blood samples, enzyme studies, genotypic studies, evoprints) made students aware of the importance of evolution - both in humans and in pathogens.

Primary field-test students completed a student evaluation of the materials after instruction. The evaluation form included items that asked whether they felt their understanding of the science content had increased by participating in the curriculum (Table 5). Mean student responses indicated that students felt that the materials increased their understanding of the role of evolution in medicine, why humans are susceptible to disease, and how natural selection informs medicine. Students reported that the difficulty of the materials was in the range of "Just Right" to "Somewhat Difficult." In response to the question "Evolution has some things to teach us about being human," over $84 \%$ of the students responded between "Agree a Little" and "Strongly Agree" and 61\% fell in either "Agree" or "Strongly Agree."

Not surprisingly, high school students across the U.S. and across different ethnic and socioeconomic groups showed low levels of understanding of evolution on the pretest. Students made statistically significant improvements
Table 6 Summary of pretest and posttest results

\begin{tabular}{lcccc}
\hline & $\begin{array}{l}\text { Pretest mean } \\
\text { number correct }\end{array}$ & $\begin{array}{l}\text { Posttest mean } \\
\text { number correct }\end{array}$ & $t$ test & $\begin{array}{l}\text { Cohen's d effect size } \\
\text { (lower, upper 95\% } \\
\text { confidence intervals) }\end{array}$ \\
\hline Complete test (10 items) & 4.47 & 5.69 & $p<.001$ & $0.7(.58, .80)$ \\
Common ancestry only (5 items) & 1.66 & 2.63 & $p<.001$ & $0.8(.70, .92)$ \\
Natural selection only (5 items) & 2.81 & 3.04 & $p<.001$ & $0.2(.10, .31)$ \\
\hline
\end{tabular}


from pretest to posttest (see Table 6). Student responses on the pre- and posttest were also examined by two of the primary conceptual areas: common ancestry and natural selection. On items related to common ancestry, students had lower pretest and posttest scores, but larger overall gains, with an effect size that falls into the "large" effect size range (Cohen's $d$ effect size $=0.8$; Cohen 1988). Students had relatively higher pretest and posttest scores for items related to natural selection, but the effect size falls into the "small" effect size range (Cohen's $d$ effect size $=0.2$ ).

An analysis of differences between groups revealed no significant differences between male and female students on posttest score. However, students who do not receive free or reduced-price lunch scored significantly higher on both the pretest and posttest than students who do receive free or reducedprice lunch. We used orthogonal contrast coding to examine whether or not there were differences between students in posttest score based on race/ethnicity, after controlling for pretest score. The findings of that analysis indicate that there was no significant difference between white students and all other racial/ ethnic groups $(B=-0.051, p=0.325)$.

The relationships between student gains and student selfreported abilities in science, students' interest in biology, and a measure of students' acceptance of evolution were explored through correlations (Table 7). Student gains on concepts related to natural selection were significantly correlated with students' interest in biology and their self-reported abilities in science, whereas student gains on concepts related to common ancestry were not significantly correlated with interest or ability. One survey item was designed as a rough gauge of students' acceptance of evolution. Student gains in understanding of neither natural selection nor common ancestry were significantly correlated with student acceptance of evolution.

\section{Discussion}

Teaching evolution is difficult. Teachers need curriculum materials that both portray evolution as modern and dynamic and that are based on the most promising instructional practices. Most of the studies on evolution education are conducted at the college level and focus on students in one classroom or geographic area (Beardsley et al. 2011). We believe that the Evolution and Medicine curriculum supplement helps fill this vital need for teaching about evolution at the high school level while emphasizing science as inquiry. A broad range of experts contributed to the development of this supplement, and preliminary evidence suggests that the curriculum is useable, feasible, and well-received by high school teachers and students.

Preliminary comparisons of our results to results from other researchers in evolution education suggest that high school students using the intervention achieved gains similar to or greater than gains achieved by students at the college level (Asterhan and Schwarz 2007; Abraham et al. 2009). This is significant because the students in the field test are younger and are presumably from a broader range of socioeconomic backgrounds than the students in the studies at the college level. For example, Bray Speth et al. (2009) used similar CINS items to three of the items that were modified for use in this study to measure student understanding of natural selection in an undergraduate introductory biology class for majors that focused on evolution. The students in their study spent a longer time learning about evolution compared to the high school students in our study. On average, teachers in our study required 12 class periods of approximately 50 minutes in length to complete the supplement (600 minutes). The undergraduate students learned about evolution through eight 80-minute class periods and four lab periods of three hours each (1,360 minutes, over twice as much time). On ten items, the college students' class average improved from 5.1 to 6.8 (no effect size reported). In both studies, students struggled the most with questions focused on variation and inheritance. Understanding common ancestry and tree interpretation showed higher gains (effect size 0.8), similar to results obtained for college students by Perry et al. (2008).

One important result from the evaluation of the field-test materials is that students made significant gains in their understandings of common ancestry and natural selection. A second important result was the lack of significant differences

Table 7 Correlations of self-reported student interest in biology, student ability in science, and acceptance of evolution, versus normalized gains in achievement

\begin{tabular}{|c|c|c|c|c|c|c|}
\hline & \multicolumn{6}{|c|}{ Normalized gain scores } \\
\hline & \multicolumn{2}{|l|}{ Total test } & \multicolumn{2}{|c|}{ Natural selection } & \multicolumn{2}{|c|}{ Common ancestry } \\
\hline & $\begin{array}{l}\text { Pearson } r \\
\text { correlation }\end{array}$ & $\begin{array}{l}\text { Significance } \\
\text { (two-tailed) }\end{array}$ & $\begin{array}{l}\text { Pearson } r \\
\text { correlation }\end{array}$ & $\begin{array}{l}\text { Significance } \\
\text { (two-tailed) }\end{array}$ & $\begin{array}{l}\text { Pearson } r \\
\text { correlation }\end{array}$ & $\begin{array}{l}\text { Significance } \\
\text { (two-tailed) }\end{array}$ \\
\hline Student interest in biology & 0.102 & 0.02 & 0.167 & $<0.001$ & 0.081 & 0.063 \\
\hline Student ability in science & 0.152 & 0.001 & 0.15 & 0.001 & 0.068 & 0.117 \\
\hline Acceptance of evolution & 0.07 & 0.112 & 0.041 & 0.36 & 0.083 & 0.056 \\
\hline
\end{tabular}


between white students and all other racial/ethnic categories. These data add to a growing research base that supports the use of inquiry-based pedagogical approaches grounded in a constructivist instructional model like the BSCS 5E instructional model. These data, along with teacher reflection data, also begin to suggest that making evolution relevant to students' lives, especially through the compelling lens of modern medical science, may lead to better student learning outcomes. A more rigorous study would be a logical next step to further investigate the impact of these curricular materials on student learning and student attitudes about science in general and evolution specifically.

\section{References}

Abraham JK, Meir E, Perry J, Herron JC. Student misconceptions about natural selection with an interactive simulated laboratory. Evol Educ Outreach. 2009. doi:10.1007/s12052-009-0142-3.

Anderson DL, Fisher KM, Norman GJ. Development and evaluation of the conceptual inventory of the natural selection. J Res Sci Teach. 2002;39:952-78.

Asterhan CSC, Schwarz BB. The effects of monological and dialogical argumentation on concept learning in evolutionary theory. J Educ Psychol. 2007;99(3):626-39.

Beardsley PM. Middle school student learning in evolution: are current standards achievable? Am Biol Teach. 2004;66:604-12.

Beardsley PM, Bloom MV, Wise SB. Challenges and opportunities for teaching and designing effective K-12 evolution curricula. In: Rosengren K, Brem SK, Evans EM, Sinatra GM, editors. Evolution challenges: integrating research and practice in teaching and learning about evolution. Oxford: Oxford University Press; 2011.

Bishop BA, Anderson CW. Student conceptions of natural selection and its role in evolution. J Res Sci Teach. 1990;27:415-27.

Bransford JD, Brown AL, Cocking RR. How people learn: brain, mind, experience, and school. Washington: National Academy Press; 2000.

Bray Speth E, Long TM, Pennock RT, Ebert-May D. Using Avida-ED for teaching and learning about evolution in undergraduate introductory biology courses. Evol Educ Outreach. 2009;2:415-28.

Bybee RW, Taylor JA, Gardner A, Van Scotter P, Carlson Powell J, Westbrook A, Landes N. The BSCS 5E instructional model: origins and effectiveness [PDF Document]. BSCS 2006 [cited 3 November 2006]. Retrieved from http://www.bscs.org/library/ BSCS_5E_Model_Full_Report2006.pdf; 2006.

Cohen J. Statistical power analysis for the behavioral sciences (2nd ed). Hillsdale, NJ: Erlbaum; 1988.

Dobzhansky T. Nothing in biology makes sense except in the light of evolution. Am Biol Teach. 1973;35:125-9.

Enattah NS, Trudeau A, Pimenoff V, Maiuri L, Auricchio S, Greco L, et al. Evidence of still-ongoing convergence evolution of the lactase persistence T-13910 alleles in humans. Am J Hum Genet. 2007;81(3):615-25.

Enattah NS, Jensen TG, Nielsen M, Lewinski R, Kuokkanen M, Rasinpera $\mathrm{H}$, et al. Independent introduction of two lactase-persistence alleles into human populations reflects different history of adaptation to milk culture. Am J Hum Genet. 2008;82:57-72.

Fowkes FJ, Allen SJ, Allen A, Alpers MP, Weatherall DJ, Day KP. Increased microerythrocyte count in homozygous $\alpha^{+}$-thalassaemia contributes to protection against severe malarial anaemia. PLoS Medicine. 2008;5(3):e56. doi:10.1371/journal.pmed.0050056.

Gerbault P, Moret C, Currat M, Sanchez-Mazas A. Impact of selection and demography on the diffusion of lactase persistence. PLoS ONE. 2009;4(7):e6369. doi:10.1371/journal.pone.0006369.

Hillis DM. Making evolution relevant and exciting to biology students. Evolution. 2007;61(6):1261-4.

Kondo S, Schutte BC, Richardson RJ, Bjork BC, Knight AS, Watanabe Y, et al. Mutations in IRF6 cause Van der Woude and popliteal pterygium syndromes. Nat Genet. 2002;32:2859.

Naegle E (2009) Patterns of thinking about phylogenetic trees: a study of student learning and the potential of tree thinking to improve comprehension of biological concepts. Unpublished Doctoral Dissertation: Idaho State University.

National Research Council. National science education standards. Washington: National Academy Press; 1996.

Passmore C, Stewart J. A modeling approach to teaching evolutionary biology in high schools. J Res Sci Teach. 2002;39:185-204.

Perry J, Meir E, Herron JC, Maruca S, Stal D. Evaluating two approaches to helping college students understand evolutionary trees through diagramming tasks. CBE Life Sci Educ. 2008;7 (2):193-201.

Sandoval WA, Reiser BJ. Explanation-driven inquiry: integrating conceptual and epistemic scaffolds for scientific inquiry. Sci Educ. 2004;88:345-71.

Smith DJ, Lapedes AS, de Jong JC, Bestebroer TM, Rimmelzwaan GF, Osterhaus AD, et al. Mapping the antigenic and genetic evolution of influenza virus. Science. 2004;305:371-6.

Tishkoff SA, Reed FA, Ranciaro A, Voight BF, Babbitt CC, Silverman JS, et al. Convergent adaptation of human lactase persistence in Africa and Europe. Nat Genet. 2007;39:31-40.

Vosniadou S. International Handbook of Research on Conceptual Change. USA: Routledge; 2008.

Wiggins G, Tighe J. Understanding by design. Expanded. 2nd ed. USA: Association for Supervision and Curriculum Development; 2005.

Williams TN, Wambua S, Uyoga S, Macharia A, Mwacharo JK, Newton CRJC, et al. Both heterozygous and homozygous $\alpha^{+}$thalassemias protect against severe and fatal Plasmodium falciparum malaria on the coast of Kenya. Blood. 2005;106(1):368-71.

Wilson CD, Taylor JA, Kowalski SM, Carlson J. The relative effects and equity of inquiry-based and commonplace science teaching on students' knowledge, reasoning, and argumentation. J Res Sci Teach. 2010;47(3):276-301.

Yavatkar AS, Lin Y, Ross J, Fann Y, Brody T, Odenwald WF. Rapid detection and curation of conserved DNA via enhanced-BLAT and EvoPrinterHD analysis. BMC Genomics. 2008;9:106.

Note: The development of the Evolution and Medicine curriculum was funded by a contract to BSCS from the National Institutes of Health with monies from the following Institutes and Centers: National Institute of General Medical Sciences, National Cancer Institute, National Center for Research Resources, National Eye Institute, National Heart, Lung, and Blood Institute, National Institute on Aging, National Institute of Allergy and Infectious Diseases, National Institute on Drug Abuse, National Institute of Dental and Craniofacial Research, National Institute of Neurological Disorders and Stroke, and the Office of the Director. Contract No. HHSH263200800031C 